Volume 2 No. 2, Desember 2017

P ISSN 2442-594X | E ISSN 2579-5708

http://journal.iainlangsa.ac.id/index.php/tibyan

\title{
KONSEP WAHYU DALAM ALQURAN \\ (Kajian Semantik)

\begin{abstract}
Concept Of Revelation In The Qur'an (Semantic Study)
\end{abstract}
\author{
Arief Muammar \\ Institut Agama Islam Negeri Langsa \\ amar.langsa@yahoo.com
}

\begin{abstract}
For prophets who are at a lower level, angels descending to them both in the conscious or dream world, will dwell in their imaginary power and the supernatural nature (revelation) which descends from the Hadhrat miah Scientific will reach their hearts. But for the Prophets who have a position higher than q uqul and angels, the delivery of revelation and the descent and descent of angels will be realized with the permission of the Nafs Nabawi. They can witness and dialogue directly with the angels especially with the angel Jibril witnessed in "the nature of 'uqul" with the form of "Tamatsul Aqli", in the Muslim world with the form "Tamatsul Mitsâli" and in the material world with the form "Tamatsul Nâsuti" and in this way they take revelations from angels.
\end{abstract}

Kata Kunci: Revelation, Qur'an, Religion.

\begin{abstract}
Abstrak
Bagi para nabi yang berada pada tingkatan yang lebih rendah, malaikat yang turun kepada mereka baik dalam alam sadar atau mimpi, akan bersemanyam di daya khayal mereka dan hakikat gaib (wahyu) yang turun dari Hadhrat 'Ilmiah akan sampai ke hati mereka. Namun bagi para Nabi yang memiliki kedudukan lebih tinggi dari 'uqul dan malaikat, penyampaian wahyu dan turun naiknya malaikat akan terealisasi dengan seizin Nafs Nabawi. Mereka dapat menyaksikan dan berdialog langsung dengan para malaikat khususnya dengan malaikat Jibril yang disaksikan di alam 'uqul dengan bentuk "Tamatsul Aqli", di alam mitsâl dengan bentuk "Tamatsul Mitsâli" dan di alam materi dengan bentuk "Tamatsul Nâsuti" dan dengan cara inilah mereka mengambil wahyu dari malaikat.
\end{abstract}

Kata Kunci: Wahyu, Alquran, Agama. 


\section{Pendahuluan}

Manusia beserta seluruh inderanya yang senantiasa bersentuhan dengan alam materi akan merasa kesulitan dalam menalar dan mengenal alam non materi (metafisik), oleh karena itu, ia cenderung menolak perkara-perkara gaib yang dibawa oleh para nabi, dan selalu saja menuntut bukti dan saksi akan hubungan mereka dengan alam gaib yang menjadi dakwah para Nabi.Masalah "Wahyu" dan bagaimana hubungan seorang nabi dengan alam gaib hingga ia dapat menerima wahyu, merupakan perkara metafisikal yang hakikatnya sulit diketahui manusia. Menurut ucapan Muhammad Hasan Qadar dan : Para urafa' yang telah berhasil mencapai Wâdy Gaib dalam perjalanan Sair Suluk-nya, menyatakan kelemahan mereka dalam mengenal hakikat wahyu. Allamah Thabathaba'i menyebut wahyu dengan "Syu'ur Marmuz" (logika misterius) yang dijadikan sebagai judul buku tulisannya. Imam Khomaini mengatakan: Mengenal hakikat wahyu bagi manusia merupakan sesuatu yang mustahil.

Faktor ketidakmampuan ini sangatlah jelas, karena memang manusia akan selalu kewalahan dalam mendeteksi perkara yang tidak pernah dijamahnya. Namun walaupun demikian, akal manusia yang selalu aktif bekerja terus mendorongnya untuk mengkaji dan mengenal hakikat wahyu, dan dengan modal premis dan basis pengetahuannya ia pun akan berupaya menafsirkan hakikat wahyu. Di sini secara ringkas kami mencoba mengkaji beberapa analisa yang ada, kemudian secara lebih terpirinci kami akan menyoroti dan membandingkan antara pengalaman keagamaan (religius) dan wahyu.

\section{Hakikat Wahyu Para Nabi}

Mendifinisikan dan mengenal wahyu sangat berkaitan dengan masalah kenabian, karena wahyu adalah salah satu produk inti kenabian. Pada poin berikutnya akan diuraikan pandangan para urafa' mengenai hakikat kenabian yang konklusinya adalah sebagai berikut: Kenabian -secara global- bercabang menjadi dua bagian "Ta'rifi" dan "Tasyri'i". Kenabian Ta'rifi adalah pesan dan pemberitaan yang berasal dari maqam dan makrifat -Aqli dan Maknawi- yang berada di alam Aql. Adapun kenabian Tasyri'i adalah pemberitaan akan ajaran-ajaran dan hukum-hukum Ilahi yang disampikan kepada umat manusia di dalam materi. Dalam kenabian ini, seorang Nabi dengan menjalani Tahdzib an-Nafs akan dapat mengangkat potensi ruhnya hingga sampai kepada tingkatan dimana ia dapat berinteraksi dengan alam Aql dan menyerap berbagai hakikat yang berada di sana dalam bentuk wahyu.

Apapun perbedaan tingkatan dan maqam yang telah dicapai oleh para Nabi, kembali kepada tingkatan dan posisi masing-masing Nabi itu sendiri. Bisa jadi dikarenakan seorang Nabi tidak berada dalam tingkatan yang tinggi, dalam mimpinya ia berinteraksi dengan salah satu $A q l$ yang berada di tingkatan lebih rendah dan ini mempresentasikan akan kejauhannya dengan Hakikat Muhammadiah, dan juga bisa jadi Nabi lainnya telah mencapai penjelmaan pertama dari Shâdir Awwal sehingga ia dapat menyaksikan dan mendengar segala hakikat gaib dengan kekuatan khayalan (Quwwah Mukhayyalah) atau kekuatan akalnya (Quwwah 'Aqilah), seperti yang 
dialami oleh Nabi Isa dan Nabi Musa As. Berdasarkan perbedaan tingkatan dan keutamaan para Nabi, kriteria wahyu dan cara interaksi mereka dengan alam Aql -di antaranya malaikat- juga akan berbeda.

Bagi para nabi yang berada pada tingkatan yang lebih rendah, malaikat yang turun kepada mereka baik dalam alam sadar atau mimpi, akan bersemanyam di daya khayal mereka dan hakikat gaib (wahyu) yang turun dari Hadhrat 'Ilmiah akan sampai ke hati mereka. ${ }^{1}$ Namun bagi para Nabi yang memiliki kedudukan lebih tinggi dari 'uqul dan malaikat, penyampaian wahyu dan turun naiknya malaikat akan terealisasi dengan seizin Nafs Nabawi. Mereka dapat menyaksikan dan berdialog langsung dengan para malaikat khususnya dengan malaikat Jibril yang disaksikan di alam 'uqul dengan bentuk "Tamatsul Aqlì", di alam mitsâl dengan bentuk "Tamatsul Mitsâli” dan di alam materi dengan bentuk "Tamatsul Nâsutì" dan dengan cara inilah mereka mengambil wahyu dari malaikat. Para urafa' meyakini hal ini dan menafsirkannya sebagai mabda wahyu. ${ }^{2}$ Sehubungan dengan ini Muhyiddin Arabi mengatakan: Nabi-nabi pembawa syariat yang menerima wahyu melalui Ruh al-Amin (malaikat Jibril) dari 'Ain alMalak ...maka harus dengan turunnya ruh-ruh ke hati mereka. Yang dimaksud dengan hati dan tempat turun dan bersemayamnya malaikat adalah kekuatan khayal muthashil para Nabi yang di dalamnya terdengar suara malaikat pembawa wahyu dimana dengan proses pembentangannya, seorang Nabi akan sampai pada kahayal munfashil (alam mitsâl). ${ }^{3}$

Selanjutnya Ibnu Arabi menuturkan: Hadhrat Khayal adalah merupakan pilar utama wahyu Ilahi bagi para ahli inayah...dan demikian pula jika malaikat menjelma seorang lelaki bagi seorang Nabi, maka itu merupakan bagian dari Hadhrat Khayal. Dalam mensarahinya, Qaisari menuliskan: Sesungguh-nya wahyu tidak akan ada kecuali dengan turunnya malaikat dan pertama turunnya pada Hadhrat Khayal kemudian pada Hadhrat Hissiah, oleh karenanya pribadi yang menyaksikannya harus memiliki kekuatan khayal yang becahaya, agar ia dapat menyaksikannya di dalam Hadhrat Khayal dan juga di dalam Mitsal Mutlaq karena ia adalah penghubung antara alam materi dengan Mitsali Mutlaq dan turun naiknya Malaikat harus melaluinya.

Sa'duddin Faraghani dengan membagi wahyu menjadi beberapa bagian, ia meyakini bahwa mendengar kalam Ilahi tanpa melaui perantara, merupakan tingkatan wahyu yang tinggi. Ia mengatakan: Tingkatan wahyu yang paling tinggi adalah mendengar kalam Ilahi tanpa melalui perantara seperti yang dialami Nabi Musa As, tingkatan selanjutnya adalah mendengarnya dengan perantara malaikat dengan bentuk tertentu atau lainnya. Dalam kesempatan lain Faraghani mengingatkan bahwa turunnya wahyu dengan perantara Malaikat adalah bentuk zahir dari proses penurunan wahyu. Namun bisa jadi dikarenakan kekuatan ruhnya, seorang Nabi dengan jalan

${ }^{1}$ Ta'liqat 'ala Syarhi Fushus al-Hikam,. Syarh Du'a as-Sahr, (cetakan Muassese, Tandzim Atsar Imam, Tehran). h.66 dan 77.

${ }^{2}$ Ibid,...h. 41 dan 180

${ }^{3}$ Al-Futuhat al-Makkiyyah, Jilid. 2, h. 78-79. 
Syuhud dan tanpa perantara dapat mengetahui muatan wahyu sebelum wahyu tersebut diturunkan melalui malaikat Jibril, hal seperti inilah yang dialami oleh Rasulullah Saw.

Imam Khomaini juga menegaskan akan kapabilitas para Nabi dalam menurunkan malaikat, beliau berkata: Sesungguhnya manusia-manusia sempurna seperti para Nabi, mereka mampu menjelmakan hakikat-hakikat dalam alam mitsâl sesuai ikhtiar mereka dan dari alam mitsâl mereka turunkan hakikat-hakikat tersebut kepada malaikat guna membebaskan orang-orang yang terbelenggu di alam materi, maka turunlah malaikat di alam mitsâli dan malaki sesuai dengan kesempurnaan kekuatan ruhani mereka (para Nabi), sesungguhnya kekuatan ruhani seorang Nabi adalah yang menurunkan malaikat di alam mitsâl dan alam malak.Dengan kata lain, ilmu para Nabi tidak dapat dibandingan dengan ilmu manusia biasa, karena ilmu mereka berasal dari ilmu Tuhan atau Lauh al-Mahfudz (Ilmu ruh suci Muhamadi) yang mereka dapatkan sesuai tingkatan dan keutamaan yang mereka miliki. Hukum-hukum yang dibawa para Nabi bukanlah hasil ijtihad mereka, sesungguhnya mereka menyingkap hakikat-hakikat yang mereka ketahui dari ilmu al-Haq (Allah Swt) atau Lauh al-Mahfudz sesuai tingkatan kesempurnaan yang mereka miliki. ${ }^{4}$

Adapun titik persamaan dari wahyu yang dimiliki para Nabi adalah sumber wahyu mereka yang kembali kepada Hakikat Muhammadiah. Berdasarkan uraian sebelumnya, Hakikat Muhammadiah adalah Shâdir Awwal dan wasilah mengalirnya anugrah Ilahi ke berbagai Wujud Imkan lainnya. Para urafa' mengumpamakan Hadhrat (Hakikat Muhammadiah) seperti sebuah cermin atau cahaya dimana gambar dan cahaya lainnya berasal dari keberadaannya, artinya keberadaan para Nabi dan juga kenabian yang mereka miliki, adalah jelmaan dan manifestasi dari keberadaan dan kenabian Hakikat Muhammadiah.

Berdasarkan hal ini, kenabian Rasulullah Saw adalah Azali dan kenabian Nabinabi lainnya muncul setelahnya (mutaakhir). Muhyiddin Arabi menuturkan: Sesungguhnya Nabi kita adalah Nabi yang Azali dengan kenabian Tasyri'i dan adapun kenabian Nabi-nabi lainnya terealisasi saat Bi'tsah (dilantik menjadi Nabi). Seluruh Nabi dari Nabi Adam As hingga Nabi akhir, tidak ada satupun dari mereka kecuali telah mengambil cahaya dari Nabi penutup meskipun wujud materinya adalah yang terakhir diutus, sesungguhnya ia ada dengan hakikatnya.

Di dalam bukunya Fazlur Rahman yang membahas tentang konsep kenabian dan wahyu Allah, kenabian dan wahyu Allah ini adalah berdasarkan kepengasihan Allah dan ketidak dewasaan manusia di dalam persepsi dan motifasi ethisnya.Para nabi adalah manusia-manusia luar biasa, yang kepekaan mereka, ketabahan mereka, karena wahyu Allah mereka terima serta yang kemudian mereka sampaikan kepada manusia dengan ulet tanpa mengenal takut.Dapat mengalihkan hati nurani ummat manusia dari ketenangan tradisional dan tensi hipomoral ke dalam suatu kawasan sehingga mereka dapat menyaksikan Tuhan sebagai Tuhan dan syetan sebagai syetan. ${ }^{5}$

\footnotetext{
${ }^{4}$ Lihat Kitab, Misbah al-Hidayah, h. 76.

${ }^{5}$ Fazlur Rahman, Tema Pokok Al-Qur'an, (Pustaka: Bandung, 1996), h.119.
} 
Kata wahyu dan kata sejenisnya digunakan dalam Alquran sebanyak tujuh delapan kali. ${ }^{6}$ Makna dasar dari kata wahyu secara bahasa adalah memahamkan sesuatu dengan cepat dan tersembunyi.Makna ini terdapat dalam penggunaan kata wahyu secara keseluruhan.

\section{Pemahaman Secara Fitrah}

Dalam al-Quran disebutkan, dalam surat an-Nahl [16] ayat 68 yang berbunyi: ${ }^{7}$

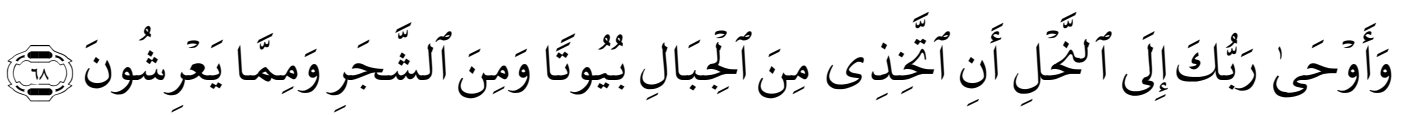

Artinya: "Dan Tuhanmu mewahyukan kepada lebah: "buatlah sarang-sarang di bukitbukit, di pohon kayu dan di tempat-tempat yang bikin manusia". (QS. an-Nahl [16]: 68 )

Syekh Mufid menjelaskan, "Yang dimaksud dengan wahyu adalah ilham yang tersembunyi.Lebah madu, tanpa ada ucapan tertentu, memahami dan mengetahui tugas-tugasnya."

Di antara perilaku lebah madu yang mengherankan adalah membuat sarang yang berbentuk segi enam yang terbuat dari malam, melakukan penjagaan terhadap sarang, melakukan perjalanan yang cukup jauh untuk dapat menemukan bungabunga,menghisap sari madu bunga-bunga tersebut, mengubah-nya menjadi madu, kembali ke sarang masing-masing, meletakkannya di dalam sarang, melakukan penjagaan terhadap ratu dan bermain-main dengan ratu lebah, dan masih banyak lagi perilaku-perilaku lebah yang sangat mengherankan. Seluruh perilaku tersebut bersumber dari insting yang ada pada lebah.Lebah madu, dalam perilaku yang indah dan mengherankan tersebut berbuat, sesuai dengan ilham yang telah diberikan oleh Allah pada mereka yang terdapat dalam diri mereka.

\section{Berlakunya Sunatullah dan Hukum Alam}

Dalam Alquran disebutkan juga tentang penciptaan alam dalam surat Fuhsilat [41] ayat $11-12$ yaitu: ${ }^{8}$

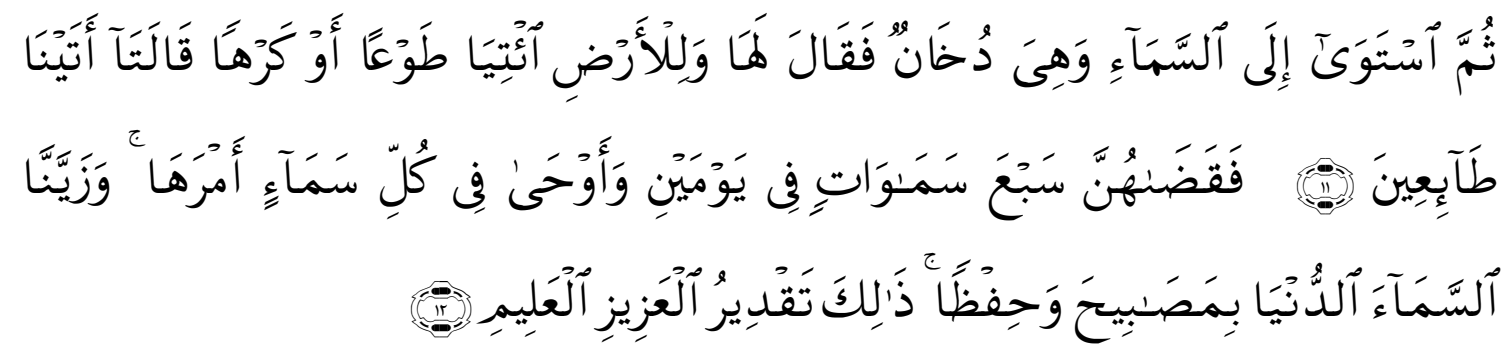

Artinya: "Kemudian Dia menuju kepada penciptaan langit dan langit itu masih merupakan asap, lalu Dia berkata kepadanya dan kepada bumi: "Datanglah kamu keduanya menurut perintah-Ku dengan suka hati atau terpaksa".

${ }^{6}$ Najar, Abdul Majid An. Khilafah: Tinjauan Wahyu dan Akal. (Jakarta: GEMA INSANI PRESS, 1999), h.11.

${ }^{7}$ Lihat Terjemahan Al-Qur'an Kementerian Agama, surat an-Nahl ayat 68.

${ }^{8}$ Lihat Terjemahan Alquran Kementerian Agama, dalam surat Fuhsilat ayat 11-12 
keduanya menjawab: "Kami datang dengan suka hati"...Maka Dia menjadikannya tujuh langit dalam dua masa. Dia mewahyukan pada tiap-tiap langit urusannya. dan Kami hiasi langit yang dekat dengan bintang-bintang yang cemerlang dan Kami memeliharanya dengan sebaik-baiknya. Demikianlah ketentuan yang Maha Perkasa lagi Maha mengetahui”. (QS. Fuhsilat [41] : 11-12)

Saat itu, diciptakan tujuh lapisan langit dalam dua hari.Kemudian, diwahyukan pada setiap langit tugas-tugasnya.Allah hiasi langit dunia dengan bintang gemintang dan Kami menjaganya.Hal yang demikian adalah kekuasaan Zat Yang Mahaperkasa dan Maha Mengetahui.

Dalam ayat lainnya, al-Quran menjelaskan, Manakala bumi digoncangkan dengan sedahsyat-dahsyatnya, bumi mengeluarkan segala beban yang dikandungnya.Manusia berkata, “Apa yang terjadi pada bumi?"Pada hari itu, bumi memberitakan beritaberitanya. Sesungguhnya Tuhannya telah mewahyukan kepadanya (QS. az-Zalzalah:1$5)$.

Allah Swt menciptakan langit dan bumi serta seluruh jagat raya ini dengan sebuah aturan berupa hukum sebab akibat.Alam diatur oleh Allah sesuai dengan at uran dan hukum-hukum tertentu.Keteraturan alam dan berjalannya secara alamiah bersumber dari pencipta alam tersebut.Mungkin yang dimaksud dengan kata wahyu Ilahi yang digunakan pada ayat seperti ini adalah makna ini yaitu petunjuk takwini (penciptaan).

Sebagian ahli tafsir menafsirkan kata wahyu yang disebutkan dalam ayat tersebut adalah wahyu yang diberikan pada penghuni langit yaitu para malaikat.Dari dua ayat tersebut, dapat dipahami dua poin berikut.Pertama, wahyu tersebut tidak melalui pembicaraan.Kedua, penerima wahyu tidak harus sesuatu yang memiliki akal.

\section{Ilham yang Dipancarkan dalam Hati}

Alquran berkenaan dengan ibu Nabi Musa as menjelaskan,

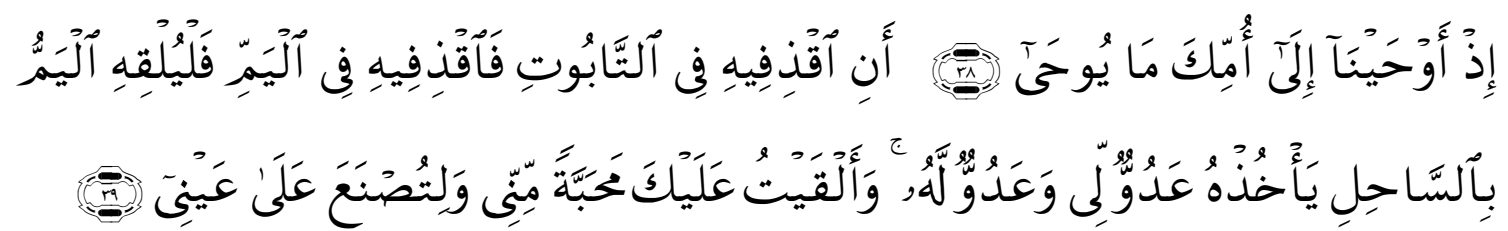

Artinya: "38. Yaitu ketika Kami mengilhamkan kepada ibumu suatu yang diilhamkan,39. Yaitu: "Letakkanlah ia (Musa) di dalam peti, kemudian lemparkanlah ia ke sungai (Nil), Maka pasti sungai itu membawanya ke tepi, supaya diambil oleh (Fir'aun) musuh-Ku dan musuhnya. dan aku telah melimpahkan kepadamu kasih sayang yang datang dari-Ku dan supaya kamu diasuh di bawah pengawasan-Ku,Maksudnya: Setiap orang yang memandang Nabi Musa a.s. akan merasa kasih sayang kepadanya". (QS. Thaha [20] : 3839) 
Ayat lainnya menerangkan, Dan Kami wahyukan kepada Ibu Musa, "Susuilah anakmu."Jika kamu takut, hanyutkan ke laut. Jangan takut dan jangan bersedih Kami kelak mengembalikannya kepadamu dan Kami jadikan dia sebagai rasul (QS. alQashash:7).

Penerima wahyu pada dua ayat tersebut adalah ibu Nabi Musa as.Wahyu yang diberikan kepadanya jelas bukan wahyu pada seorang nabi melainkan sebuah bentuk pemahaman yang tersembunyi dan tertanam dalam hati. Hal tersebut adalah ilham, baik dalam tidur maupun dalam keadaan sadar.

\section{Isyarat}

Al-Quran menerangkan, Zakariya berkata, "Tuhanku, berilah aku tanda."Allah berfirman, "Tandamu adalah jangan engkau berbicara dengan manusia selama tiga hari tiga malam berturut-turut." Kemudian dari mihrabnya, ia keluar menjumpai kaumnya, lalu mewahyukan (mengisyaratkan) pada mereka untuk memuji Allah sepanjang pagi dan petang (QS. Maryam:10-11).

Dalam ayat yang lainnya, alquran menjelaskan tentang kisah Nabi Zakariya sebagai berikut, Zakariya berkata, "Tuhanku, berilah aku sesuatu sebagai tanda."Allah berfirman, "Tandamu adalah jangan kau berbicara dengan manusia selama tiga hari kecuali dalam bentuk simbol (isyarat). Banyaklah mengingat Tuhanmu dan bertasbihlah kepada-Nya di pagi dan petang." (QS. Ali Imran:41).

Pada kedua ayat di atas, pemberi wahyu (isyarat) adalah Nabi Zakariya dan penerima wahyu adalah kaumnya.Wahyu juga bermakna memahamkan sesuatu dalam bentuk isyarat yang hanya dipahami oleh orang yang dituju sebagaimana yang disebutkan pada ayat ke-41 surah Ali Imran, yang menggunakan kalimat, illa ramza, "kecuali simbol".Kandungan dari wahyu juga berupa bertasbih pada Allah di setiap pagi dan petang.

\section{Wahyu pada Hawariyyun}

Alquran menerangkan, Saat Kami wahyukan kepada para Hawari untuk beriman kepada-Ku dan kepada utusan-Ku, mereka berkata, "Kami beriman dan kami bersaksi bahwa kami adalah orang-orang Muslim.” (QS. al-Maidah:111).

Pemberi wahyu dalam hal ini adalah Allah dan penerima wahyu adalah para Hawari dan sahabat-sahabat Nabi Isa as. Sebagian para penafsir memungkinkan bahwa para Hawari adalah para nabi. Oleh karena itu, wahyu pada mereka adalah wahyu dalam istilah. Andaikan kenabian mereka tidak dapat dibuktikan, maka kata wahyu yang digunakan dalam ayat tersebut bermakna pancaran dalam hati atau ilham.Nampaknya kata wahyu dalam ayat ini bermakna demikian.

\section{Wahyu pada Malaikat}

Alquran menjelaskan, Manakala Tuhanmu mewahyukan kepada malaikat, "Aku bersama kalian. Kukuhkanlah langkah orang-orang Mukmin.” (QS. al-Anfal:12). 
Pada ayat tersebut, pemberi wahyu adalah Allah dan penerima wahyu adalah para malaikat. Akan tetapi wahyu tersebut bukanlah wahyu kenabian dan bukan pula dengan menciptakan pembicaraan atau menciptakan suara karena para malaikat sebagaimana yang telah ditetapkan dan dibuktikan bahwa mereka tidaklah berjasad atau tidak memiliki materi.

\section{Wahyu Setan}

Alquran menerangkan, Sesungguhnya setan-setan mewahyukan kepada pengikut mereka agar berdebat dengan kalian. Jika kalian menaati mereka, kalian tergolong orang-orang musyrik (QS. al-An'am:121).

Allah berfirman, Demikianlah Kami jadikan pada setiap nabi, setan-setan dari golongan jin dan manusia yang sebagian mewahyukan kepada sebagian lainnya ucapanucapan yang indah tetapi menipu. Andaikan Tuhanmu menginginkan, mereka tidak dapat melakukan hal tersebut. Namun, Allah membiarkan mereka dengan kedustaan yang mereka lakukan (QS. al-An'am:112).

Pemberi wahyu dalam hal ini adalah setan dari jenis jin dan manusia yang menyampaikan sesuatu yang menyesatkan secara tersembunyi pada pengikut mereka. Oleh karena itu, wahyu juga bermakna ucapan yang tersembunyi atau waswas yang disampaikan ke telinga mereka masing-masing sebagaimana setan-setan dari golongan jin adalah pemberi wahyu, mereka meniupkan waswas dalam hati manusia yang sesat.

\section{Wahyu pada Para Nabi}

Kendatipun kata wahyu juga digunakan untuk selain para nabi sebagaimana yang telah kami sebutkan.Akan tetapi, kata wahyu lebih banyak digunakan untuk para nabi.Sebagai contoh, dalam Alquran disebutkan, Sesungguhnya Kami telah mewahyukan kepadamu sebagaimana Kami telah mewahyukan kepada Nuh dan para nabi setelahnya. Kami wahyukan kepada Ibrahim, Ismail, Ishaq, dan Ya'qub serta Kami wahyukan kepada Asbath, Isa, Ayyub, Yunus, Harun, dan Sulaiman serta Kami berikan Zabur kepada Daud (QS. an-Nisa:163).

Alquran menjelaskan, Kami kisahkan kepadamu melalui wahyu Alquran tentang kisah-kisah terbaik.Kendatipun kalian lalai setelah hal itu (QS. Yusuf:3).

Dalam ayat lainnya, Alquran menjelaskan, Katakan, "Apakah kesaksian yang paling besar?"Katakan, "Allah menjadi saksi antara aku dan kalian.Diberikan wahyu kepadaku berupa Alquran ini untuk memberi peringatan kepada kalian dan orang-orang yang Alquran sampai kepada mereka." (QS. al-An'am:19).

Masih terdapat puluhan ayat-ayat lainnya yang pada pembahasan mendatang akan kami sampaikan pada para pembaca. Pada ayat-ayat semacam ini, pemberi wahyu adalah Allah Swt dan penerima wahyu adalah para nabi yang sepanjang sejarah dipilih oleh Allah sebagai utusan-utusan-Nya.Kandungan dari wahyu adalah hakikat-hakikat, pengetahuan, dan perintah-perintah dari Allah Swt bagi manusia.Wahyu bagi para nabi meskipun secara bahasa - penyampaian sesuatu pada yang dituju secara tersembunyi dan sangat cepat - memiliki kesamaan dengan wahyu-wahyu lainnya, namun memiliki 
perbedaan yang mendasar serta menyeluruh.Hal ini kita bahas dalam pembahasan mendatang. ${ }^{9}$

\section{Beberapa Persfektif Mengenai Hakikat Wahyu}

\section{Perspektif Psikologis}

Sebagian Orientalis mengatakan bahwa wahyu adalah buah dari keyakinankeyakinan yang terkandung dalam jiwa dan batin para Nabi. Para nabi yang memiliki pribadi yang luhur dan hati yang bersih sangat berkeinginan membimbing dan memberi petunjuk kepada umat manusia, benak mereka senantiasa terobsesi untuk mencari solusi yang tepat guna menyelamatkan manusia dari penyembahan berhala dan segala kecenderungan hawa nafsu dan duniawi. Dengan berlalunya masa, kondisi tersebut semakin menguat dan pada akhirnya para nabi berimajinasi bahwa ada pesan atau perintah suci yang turun kepada mereka dan memerintahkan mereka untuk memberi petunjuk kepada umat manusia.

Akar sejarah pandangan di atas kembali ke masa keemasan ilmu Psikologi dan metafisik yang mencuat di Barat.Farid Wajdi memaparkan dalam Dâiratul Ma'ârif-nya bahwa hingga abad enam belas para ilmuan Barat percaya akan wahyu serta kemetafisikannya, namun dengan maraknya empirisme dan filsafat materialis, mereka mulai mengingkari segala sesuatu yang metafisik seperti hipnotis, meramal (tenung), wahyu dan lainnya, akan tetapi dengan maraknya ilmu-ilmu yang berbau metafisis seperti ilmu yang berkenaan dengan ruh, ilmu tenung, dan lainnya- yang mencuat pada tahun $1848 \mathrm{M}$, telah memaksa mereka untuk merevisi kembali pandangannya tentang wahyu, namun meskipun demikian mereka tetap saja menafsirkannya sesuai dengan doktrin empirisme dan psikologi. ${ }^{10}$

\section{Perspektif Sosiologis}

Kelompok ini menggangap bahwa wahyu bukanlah hasil bisikan (ilham) dan kondisi kejiwaan serta ego manusia, akan tetapi ia merupakan hasil karya dan intuisi sebagian orang-orang jenius.Perjalanan sejarah dan kondisi sosial banyak menelurkan orang-orang jenius dalam barbagai aspek, para nabi tidak lain adalah bagian dari para jenius tersebut yang dengan kecerdasan yang tinggi dan penguasaan terhadap kondisi sosial, mereka mampu merumuskan serentet undang-undang sosial dan individu demi memberi petunjuk kepada umat manusia, undang-undang inilah yang kemudian disebut dengan "agama".Kebanyakan sosiolog Barat menginterpretasikan agama dan wahyu secara materialistis. Emile Durkheim megatakan: Pemikiran Lahut (keagamaan) yang ada dalam benak masyarakat berakar dari masyarakat itu sendiri. ${ }^{11}$

\section{Persfektif Filosofis}

\footnotetext{
${ }^{9}$ Hasution, Harun, Akal Dan Wahyu Dalam Islam., (UI Press: Jakarta: 1986), h. 106-110.

${ }^{10}$ Dairatul Ma'arif, jld 10, h. 712

${ }^{11}$ Din Pazuhi, terjemahan Bahauddin Khuramsyahi, Jld 1, h. 109
} 
Para filosof meyakini bahwa selain alam materi terdapat alam lainnya yang disebut dengan alam Aql dan alam Mitsâl (berdasarkan teori filsafat Iluminasi) dimana seluruh fenomena yang ada di dunia ini terlukiskan secara abstak di alam tersebut, dikarenakan substansinya yang berbeda dengan alam duniawi ia sangat jauh dari jangkauan manusia, namun dengan kedudukan yang tinggi, seorang nabi dapat mancapainya. Jiwa manusia dengan melepaskan belenggu materi dan melakukan penyucian diri, ia akan mampu berinteraksi dengan alam Aql dan alam Mitsal dan menagkap perkara dan berita gaib yang tersimpan di dalamnya, menyaksikan Malaikat dan mendengar ucapannya dapat terjalin dengan kekuatan nalar dan imajinasi seorang nabi. Dengan menyaksikan wujud Aqli dan Mitsâli Malaikat, seorang nabi dengan kekuatan imajinasinya dapat melihat jelmaan Malaikat serta mendengar ucapannya.

\section{Perspektif Teologis}

Pandangan yang tersohor dalam teologi Islam dan teologi Nasrani menyatakan bahwa wahyu adalah lafaz (kata-kata), pesan dan wejangan yang diturunkan dari Tuhan -baik secara langsung maupun melalui Malaikat- kepada seorang nabi. Diyakini pula bahwa seorang nabi diharuskan untuk menyampaikan pesan-pesan Ilahi tersebut. Selain itu menurut pandangan ini (khususnya teologi Islam) wahyu yang diturunkan kepada Nabi Saw (al-Qur'an) seratus persen lafaz-lafaznya sesuai dengan apa yang telah dituturkan dan Nabi Saw sama sekali tidak menambahkan atau mengurangi satu kata atau kalimat pun darinya, berbeda dengan apa yang diyakini sebagian orang bahwa al-Qur'an turun kepada Rasul Saw hanya berupa pemahaman dan makna, Rasul sendirilah yang telah meletakkan lafaz-lafaz dan kalimat-kalimat yang ada.

\section{Pandangan Filsuf Muslim Terhadap Wahyu}

Sebagian Pemikir Muslim menerima interpretasi di atas, Syaikh Muhammad Abduh setelah menukil definisi wahyu yang umum dikenal dengan "Pesan Tuhan", ia mengemukakan pendapatnya seraya mengatakan: Adapun pendapat kami -tentang wahyu- kami katakan bahwa ia adalah pengetahuan ('irfân) yang didapati seseorang dalam jiwanya dengan dibarengi keyakinan bahwa ia datang dari sisi Tuhan, baik dengan perantara ataupun tidak, adapun yang pertama (yang dengan perantara) dengan perantara suara yang sampai ke pendengarannya atau dengan lainnya.

Muhammad Iqbal adalah salah satu pemikir kontemporer Muslimin yang selain menerima pendekatan empiris terhadap permasalahan makrifat, penafsiran hakikat agama, dan memprkenalkan filsafat (filsafat Yunani dan akal murni), menyambut penafsiran pengalaman keagamaan dalam bentuk berseberangan dengan Alquran. Ia mengistilahkan wahyu dengan "kondisi batin" dan "kesadaran batin" yang memiliki kesatuan esensi dengan pengalaman agama dan pengalaman batin lainnya. Selanjutnya ia menuturkan: Dapat dikatakan bahwa seorang Nabi memiliki kesadaran dan pemahaman batin semacam ini dimana pada kondisi ini "pengalaman kesatuan" 
mempunyai kecende-rungan padanya melewati batasannya. Dari sisi kualitas pengalaman batin tidak berbeda dengan pengalaman kenabian. ${ }^{12}$

Iqbal menganggap bahwa basis wahyu dan pengalaman keagamaan berasal dari kekuatan insting yang juga dapat ditemukan -dengan berbeda- pada tumbuhan dan binatang.Keterkaitan dengan sumber keberadaan ini sama sekali tidak hanya terbatas untuk manusia. Penggunaan kata wahyu dalam al-Qur'an melaporkan bahwa kitab ini menganggap wahyu sebagai tahap kehidupan tertentu dan sudah barang tentu kriteria dan polanya adalah berbeda berdasarkan tingkatan keragaman kesempurnaan kehidupan. Menurutnya (Iqbal) landasan dan basis wahyu adalah dorongan insting dan kekuatan jiwa di masa kanak-kanak yang tetap kokoh saat berhadapan dengan beragam hambatan seperti akal dan kehidupan duniawi. ${ }^{13}$

Pada masa kanak-kanak, kekuatan jiwa dapat mencuatkan sesuatu yang kami sebut dengan "Kesadaran Kenabian" yang dengan mediasinya pandangan dunia seseorang dan jalan kehidupan dapat terpelihara dengan cara mengikuti perintahperintah, prinsip-prinsip serta memilih petunjuk dan hidayah yang telah ada dan tersedia.

Sourush mengatakan: Kenabian adalah sejenis pengala-man dan kasyf dan seterusnya, Nabi juga adalah manusia, agama adalah konklusi pengalaman-pengalaman individul dan sosialnya, sekarang ini pada masa kegaiban (ketiadaan) Nabi, pengalaman-pengalaman dalam (batin) dan di luar dirinya pun harus terus berlanjut.

Mujtahid Syubastary mengatakan: Wahyu adalah semacam pengalaman keagamaan. Sebagian lainnya menuliskan: Wahyu adalah bagian dari pengalaman keagamaan dan seterusnya menurut prinsip agama-agama Tauhid, wahyu memiliki satu arti yaitu "Pengalaman Ketuhanan", oleh karena itu minimal ia dapat dikatakan sebagai salah satu misdak dari pengalaman keagamaan.

\section{Wahyu Dalam Teologi Kristiani}

Dalam teologi Kristiani banyak terdapat indikasi yang menyatakan bahwa wahyu berakar dari pengalaman keagamaan. Para pendeta Nasrani meyakini bahwa Tuhan tidak menurunkan pesan-pesan dan wahyu kepada Nabi Isa As, akan tetapi ruh suci Ilahi telah menjelma pada diri al-Masih, dan diri al-Masih sendiri adalah wahyu yang diturunkan. Peryataan ini sesuai dengan lahiriah sebagian ayat perjanjian baru yang mengatakan: "Tuhan dalam diri al-Masih". ${ }^{14}$

Para teolog liberal Nasrani mengatakan bahwa wahyu adalah kehadiran dan manifestasi Tuhan dalam kehidupan al-Masih dan seluruh Nabi Bani Israil, dengan ini mereka telah mengingkari wahyu yang berbentuk lafaz dan kata-kata (pengiriman kitab samawi). Berkaitan dengan ini Barboure mengatakan: Para teolog liberal menyatakan: h. 155

${ }^{12}$ Iqbal, Muhammad, The Recontraction Of Religion Thought In Islam, (New Delhi: Barvan, 1981),

${ }^{13}$ Ibid,.h. 156

${ }^{14}$ Aritonang, Jan s. Berbagai Aliran di Dalam dan di Sekitar Geraja. (Jakarta: PT BPK Gunung Mulia, 2008), h. 23. 
tidak dapat dipungkiri bahwa kitab suci (Injil) bukanlah wahyu yang diturunkan secara langsung namun ia telah ditulis oleh manusia dan dengan antusias mereka membacanya. Sebagai ganti dari pengingkaran terhadap wahyu, sebagian dari mereka (teolog liberal) mengungkapkan persepsi baru mengenai wahyu: Tuhan telah menurunkan wahyu, namun bukan dengan mendikte sebuah kitab suci, akan tetapi dengan kehadiran-Nya dalam kehidupan al-Masih dan Nabi-Nabi Bani Israil, oleh karenanya kitab suci bukanlah wahyu secara langsung, namun ia merupakan bukti atas refleksi wahyu dalam pengalaman keagamaan manusia. Bart menyatakan bahwa wahyu yang sebenarnya adalah pribadi al-Masih itu sendiri, kalimat dalam bentuk manusia. Kitab suci adalah hasil tulisan manusia yang memberi kesaksian akan keyataan wahyu ini. ${ }^{15}$

Pandangan ini merebak luas dalam teologi Protestan pada abad kedua puluh, dimana mereka mendakwa bahwa pembaharu agama Nasrani abad keenam belas seperti Luther dan Calhoun, bahkan lebih dari itu dalam perjanjian baru dan gereja pertama telah dinyatakan bahwa kredibilitas wahyu terdapat pada diri Masih sendiri bukan pada kitab suci.

\section{Hakikat Wahyu Menurut Para Urafa'}

Para urafa' juga memandang hakikat wahyu sebagai pengalaman keagamaan, namun pangalaman keagamaan yang mereka utarakan memiliki beberapa perbedaan dengan apa yang dikatakan para ilmuan Barat. Untuk mengenal lebih jeluk, kita akan menyoroti poin-poin berikut: Poin Pertama, Para urafa' membatasi wujud hakiki hanya pada Dzat Ilahi dan segala keberadaan selain-Nya hanya merupakan manifestasi dari keberadaan-Nya yang hakiki. Mereka menyebut Dzat Allah Ta'ala yang murni dari asma dan sifat dengan "Maqam Ahadiyat", "Gaib Maghib" dan "Maqam "Ama". Setelah "Maqam Ahadiyat" adalah "Maqam Wâhidiyat" dimana pada tingkatan ini asma' dan sifat Ilahi menjadi sorotan dan perhatian, alam ini disebut dengan "A'yân Tsâbitah", "Hadhrat Ilmiah" dan "Syahadah Mutlaqah". Dalam alam ini -secara abstrak- terdapat inti keberadaan alam lainnya yang sebenarnya alam ini merupakan pemberi dan penganugerah keberadaan bagi alam imkân, oleh karena itulah ia disebut dengan "Faidh Aqdas", namun sesuai dengan kaidah "Al-wâhidu la yashduru 'anhu illa al-wâhid' (Sesuatu yang satu tidak akan muncul darinya kecuali yang satu pula) maka ia adalah makhluk tanpa perantara yang disebut "Aql Awwal" menurut para filosof atau "Wujud Munbasit wa 'Aam" menurut istilah urafa'. Wujud mumkin pertama ini juga merupakan penganugrah keberadaan bagi wujud lainnya, dimana antara satu dengan alam lainnya memiliki hubungan sebab dan akibat. ${ }^{16}$

Kedua, Menurut keyakinan para urafa' dan kebanyakan filosof, Shâdir Awwal dan Wujud Munbasith adalah Ruh Muhammad Saw yang mendapat pengagungan

\footnotetext{
${ }^{15}$ Boehlke, Robert R. Sejarah Perkemabagan Pikiran dan Praktek Pendidkan Agama Kristen. (Jakarta: Gunung Mulia, 2009). h. 8

${ }^{16}$ Zaini Dahlan,Dkk, Mukadimah Al-Qur'an dan Tafsirnya (Yogyakarta:PT. Dana Bakti Wakaf,1991) h.13.
} 
sebagai manifestasi pertama dan makhluk tanpa perantara Allah Swt. Setelah ruh Nabi Islam, diciptakanlah ruh para Imam suci dan Nabi sebagai Uqul Mujarradah. Aql dan ruh malaikat termaksud Jibril diciptakan setelah ruh Nabi dan Imam yang sebenarnya adalah makhluk dan anugrah ruh suci Rasulullah Saw. Dalam alam Aql, utusan dan pembawa pesan pertama adalah ruh Rasulullah Saw yang merupakan Shâdir Awwal yang dengan menempuh perjalanan (Sair) di alam Hadhrat Ilmiah dan Maqam Wâhidiyat dapat mentransfer hakikat-hakikat asma dan sifat Ilahi kepada Aql lainnya termasuk Aql para Nabi dan Malaikat, dari sini jelaslah makna dan maksud dari hadis Nabi Saw yang berbunyi "Aku telah menjadi seorang Nabi (pembawa pesan) di saat Adam As berada di antara air dan tanah", "Adam As dan siapa saja selainku berada di bawah benderaku".

Yang ketiga, Wahyu dan pesan-pesan gaib diturunkan kepada para nabi melaui para malaikat dari alam Aql dan di batas akhir Aql Awwal yang tidak lain adalah ruh Muhammadi Saw yang dengan perantaraannya Allah akan menurunkan wahyu-Nya, dengan demikian jelaslah keagungan dan keistimewaan ruh Rasulullah Saw dan para Imam Maksum dibanding para nabi lainnya serta seluruh kitab suci yang diturunkan kepada mereka, bahkan mereka (Rasul dan Imam suci) lebih mulia dibanding al-Qur'an itu sendiri karena wujud suci mereka merupakan sumber dan perantara turunnya wahyu dan al-Qur'an.

Ke Empat, Alam dunia dan manusia merupakan alam mumkin yang paling rendah, dimana sumber keberadaannya pun berasal dari alam Aql. Ruh manusia juga telah ada di alam Aql dengan berbentuk wujud yang simpel dan tunggal yang kemudian turun di alam dunia yang berada di bawahnya. Yang patut disoroti di sini adalah perpindahan ruh dari alam Aql ke alam dunia bukan berarti meniscayakan kekosongannya di alam Aql, namun keberadaan ruh manusia tetap terjaga di sana, demikian pula halnya dengan Nafs Nabawi. Oleh karena itu, pada hakikatnya manusia memiliki dua sisi dan wujud. Wujud pertama manusia adalah keberadaannya sebelum di dunia yang berupa Aql dan abstrak yang berada di alam 'Uqul dan merupakan A'yan Tsâbitah. Wujud kedua manusia adalah keberadaan materinya yang saat ini berada di alam materi dan terdiri dari ruh dan badan. Nafs manusia karena ketergantungannya dengan materi -atau menurut istilah Hikmah Muta'aliyah, penemuan Nafs (non-materi) yang tadinya dari materi dikarenakan Harakah Jauhariah (gerakan substansial), tidak memiliki kesempurnaan metafisikal, namun ia tetap memiliki potensi untuk menggapai dan menyerap kesempurnaan-kesempurnaan tersebut. ${ }^{17}$ Oleh karena itu, dengan melalui fase-fase dan empat perjalanan (Asfar Arba'ah), setiap manusia akan mampu mencapai kesempurnaannya dan tersambung dengan Ain Tsâbit-nya dan seluruh Aql lainnya.

Adapun yang Kelima, Berdasarkan uraian sebelumnya jelaslah bahwa manusia membutuhkan petunjuk dan pertolongan Ilahi dengan perantara para Malaikat, namun Nafs para nabi khususnya Nabi Islam hanya butuh kepada pertolongan Ilahi (tanpa perantara Malaikat). Dengan Tahdzibu an-Nafs yang dijalani di dunia ini, Rasulullah

\footnotetext{
${ }^{17}$ Ibid.,h.16
} 
Saw menyiapkan dirinya untuk Mi'raj dan berinteraksi dengan 'Ain Tsâbitah dan Wujud Bashit-nya, dan setelah melalui serangkaian fase, beliau akan mencapai Maqam Nubuwwah yang berada di alam 'Uqul dan menurunkannya di alam materi.

Jadi pada hakikatnya, wahyu yang di sampaikan oleh Rasul Saw berasal dari "Hakikat Muhammadiah" dan "Wujud Munbasith". Dengan kata lain, wujud materi Rasulullah Saw telah tersambung dengan wujud mujarrad-nya, dan wahyu yang beliau sampaikan kepada umat adalah hakikat mujarrad yang telah menjelma menjadi uraian wahyu yang rinci dan berdimensi materi. Kalaupun para malaikat seperti malaikat Jibril memiliki andil dalam merealisasikan tugas Nabi tersebut (menyampaikan wahyu), tidak lebih ia hanya sebagai pendamping Nafs Nabawi atau penyampai pesan dari Hakikat Muhammadiah kepada Nafs Nabawi.

\section{Penutup}

Sebagian pakar bahasa memahami bahwa penekanan makna kata wahyu terletak pada pengertian cepat dan bukan pada makna kesamarannya. Kesamaran pada pengertian kata tersebut justru terambil dari penganggapan makan cepat. Isyarat yang disampaikan dengan cepat biasanya akan membuatnya samar. Dan hal itu sesuai dengan makna bahasanya, seperti dikatakan dalam contoh: mautun wahyun (kematian yang cepat), Al waha $A l$ waha (cepat-cepat!/ perintah agar bergegas). Dalam hadis juga

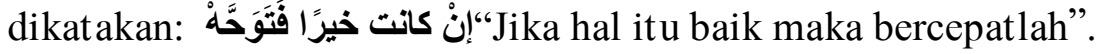

Wahyu yang diterima oleh para nabi dan rasul Allah SWT adalah komunikasi yang terjadi antara Allah SWT dan hamba-hamba pilihan-Nya tersebut. Komunikasi tersebut secara samar dan tidak mampu dipahami prosesnya oleh pihak ketiga yang tidak terlibat dalam kontak komunikasi tersebut. Komunikasi tersebut terkadang terjadi secara langsung tanpa perantara apapun atau siapapun, dan terkadang terjalin melalui perantaraan malaikat yang sebelumnya telah diberi wahyu, agar ia menyampaikan pesan Allah tersebut kepada seorang nabi. Orang yang berkerhormatan berkomunikasi dengan Allah, Tuhan Yang Maha Agung disebut Nabi atau Rasul. 


\section{DAFTAR PUSTAKA}

Alwi Shihab, Islam Inklusif, Menuju Sikap Terbuka Dalam Beragama, Cet.V, Bandung.1999

Aritonang, Jan s. Berbagai Aliran di Dalam dan di SekitarGeraja. Jakarta: PT BPK Gunung Mulia, 2008.

Al-Futuhat al-Makkiyyah, Jus. 2.

Boehlke, Robert R. Sejarah Perkemabagan Pikiran dan Praktek Pendidkan Agama Kristen. Jakarta: Gunung Mulia, 2009.

Departemen Agama RI, Al-quran dan Terjemahan, Cet.I. Jakarta: Bumi Aksara 2009.

Dairatul Ma'arif, jld 10

Din Pazuhi, terjemahan Bahauddin Khuramsyahi, Jld 1

Fazlur Rahman, Tema Pokok Al-Qur'an, Pustaka: Bandung, 1996.

Harun Nasution , Akal Dan Wahyu Dalam Islam., UI Press: Jakarta: 1986

Iqbal, Muhammad, The Recontraction Of Religion Thought In Islam, New Delhi: Barvan, 1981

Misbah al-Hidayah

Najar, Abdul Majid An. Khilafah: Tinjauan Wahyu dan Akal. Jakarta: GEMA INSANI PRESS, 1999.

Ta'liqat 'ala Syarhi Fushus al-Hikam,. Syarh Du'a as-Sahr, cetakan Muassese, Tandzim Atsar Imam, Tehran.

Zaini Dahlan,MA. Dkk, Mukadimah Al-Qur'an dan Tafsirnya Yogyakarta:PT. Dana Bakti Wakaf,1991 